\title{
Orthognathic surgery and temporomandibular joint symptoms
}

\author{
Hwi-Dong Jung ${ }^{1}$, Sang Yoon Kim², Hyung-Sik Park ${ }^{1}$ and Young-Soo Jung ${ }^{1 *}$
}

\begin{abstract}
The aim of this article is to review temporomandibular joint symptoms as well as the effects of orthognathic surgery(OGS) on temporomandibular joint(TMJ). The causes of temporomandibular joint disease(TMD) are multifactorial, and the symptoms of TMD manifest as a limited range of motion of mandible, pain in masticatory muscles and TMJ, Joint noise (clicking, popping, or crepitus), myofascial pain, and other functional limitations. Treatment must be started based on the proper diagnosis, and almost symptoms could be subsided by reversible options. Minimally invasive options and open arthroplasty are also available following reversible treatment when indicated.

TMD manifesting in a variety of symptoms, also can apply abnormal stress to mandibular condyles and affect its growth pattern of mandible. Thus, adaptive developmental changes on mandibular condyles and post-developmental degenerative changes of mandibular condyles can create alteration on facial skeleton and occlusion. The changes of facial skeleton in DFD patients following OGS have an impact on TMJ, masticatory musculature, and surrounding soft tissues, and the changes of TMJ symptoms. Maxillofacial surgeons must remind that any surgical procedures involving mandibular osteotomy can directly affect TMJ symptoms, thus pre-existing TMJ symptoms and diagnoses should be considered prior to treatment planning and OGS.
\end{abstract}

\section{Introduction}

Dentofacial Deformity (DFD) is derived from many factors including genetic predisposition, environmental exposure, childhood facial trauma or infection, cyst or tumor, parafunctional habit causing developmental malocclusion, unilateral condylar hyperplasia, mandibular hypoplasia, prior surgical procedures, or temporomandibular joint disorder(TMD) [1]. Patients with dentofacial deformity (DFD) require an orthognathic surgery (OGS) for an improved facial profile and a correction of skeletal malocclusion and asymmetry. The motivating factors for patients undergoing OGS are to improve mastication, speech, and swallowing functions as well as facial esthetic and psychosocial factors [2]. The mandibular condyle is one of the anatomic structures that consist of TMJ, and the position of condyles in relation to temporal bone can be altered via various movement during OGS. Thus, OGS can affect both functional and

\footnotetext{
*Correspondence: ysjoms@yuhs.ac

${ }^{1}$ Department of Oral \& Maxillofacial Surgery, Yonsei University College of Dentistry, Seoul, South Korea

Full list of author information is available at the end of the article
}

esthetic components including mastication, promounciation, and TMJ functions.

Tempromandibular joint disorders (TMDs) include any clinical conditions associated with masticatory musculature, temporomandibular joint (TMJ), surrounding bony and soft tissue components, and any combinations of these structures. The symptoms of TMD manifest as a limited range of motion of mandible, pain in masticatory muscles and TMJ, Joint noise (clicking, popping, or crepitus), myofascial pain, and other functional limitations [3]. The positional changes of mandible, maxilla, or both jaws during OGS, can affect TMJ, masticatory musculature, its surrounding soft tissue, and TMD symptoms. Therefore, maxillofacial surgeons must carefully evaluate patients for presence of any TMJ symptoms preoperatively, and formulate treatment plans accordingly to prevent worsening of TMD symptoms. The purpose of this article is to review the publications on TMD as well as the effects of OGS on TMJ.

\section{Tempromandibular joint disorders}

Causes \& epidemiology

In 1930's, JB Costen, an otolaryngologist, stated that TMD is a different disease process from otalgia, and is a 
condition derived from structural malalignment between mandible and cranium which requires a treatment coordination with dentists. The etiology of TMD was initially focused on dental occlusion for the next 50 years. However, it is now known that the causes of TMD are multifactorial including parafunctional habits (eg, nocturnal bruxing, tooth clenching, lip or cheek biting), emotional distress, acute trauma to the jaw, trauma from hyperextension (eg, dental procedures, oral intubations for general anesthesia, yawning, hyperextension associated with cervical trauma), instability of maxillomandibular relationships, laxity of the joint, comorbidity of other rheumatic or musculoskeletal disorders, poor general health, and an unhealthy lifestyle [4,5] (Figure 1).

Approximately 6 to $12 \%$ of population experience TMD symptoms, however only $5 \%$ of population manifests symptoms that require treatment [6]. TMD symptoms have a predilection for woman and age group between 20 to 40's [7]. Some study suggested an elevation of estrogen level in female patients [4] and hormonal influences as one of the causes of TMD [8-10], however this hypothesis has not been substantiated.

\section{Examination}

Obtaining a detailed history from patients using TMD symptoms questionnaire is important prior to physical examination. During the initial consultation, chief complaints and history of present illness including TMD related symptom location, onset of occurrence, condition and character, alleviating or aggravating factors, and timing must be reviewed. Then, a focused physical examination is performed to identify the causes of symptoms and diagnosis. The range of motion of mandible is measured at active and passive maximum interincisal distance as well as at the onset of pain. When TMD symptoms are present, the location and onset of the pain are further investigated. The examination for muscles of mastication involves palpation of each muscle group and observation for any pain, spasms, or fasciculation. TMJ palpation is useful for identifying intracapsular pain, joint noise, and translation. Also TMJ loading test using tongue blade biting can be applied for evaluate intracapsular pain [11] (Table 1).

Panoramic radiograph is a good screening tool for mandibular condyles and corresponding glenoid fossa relationship. For more detailed anatomic structure evaluation, multi-slice computed tomography (CT) or cone-beam computed tomography (CBCT) can be used. CT scans including CBCT is an excellent radiographic modality to evaluate mandibular condyle morphology, anatomic position, cortical erosion, presences of cyst or tumor, and ankylosis (Figure 2). The gold standard imaging modality for the disc and soft tissue surrounding TMJ is magnetic resonance image (MRI) [12], and the changes in disc position and location, morphology, and degenerative changes can be confirmed (Figure 3). However, MRI alone is not sufficient to formulate treatment plan, and other clinical findings are incorporated to

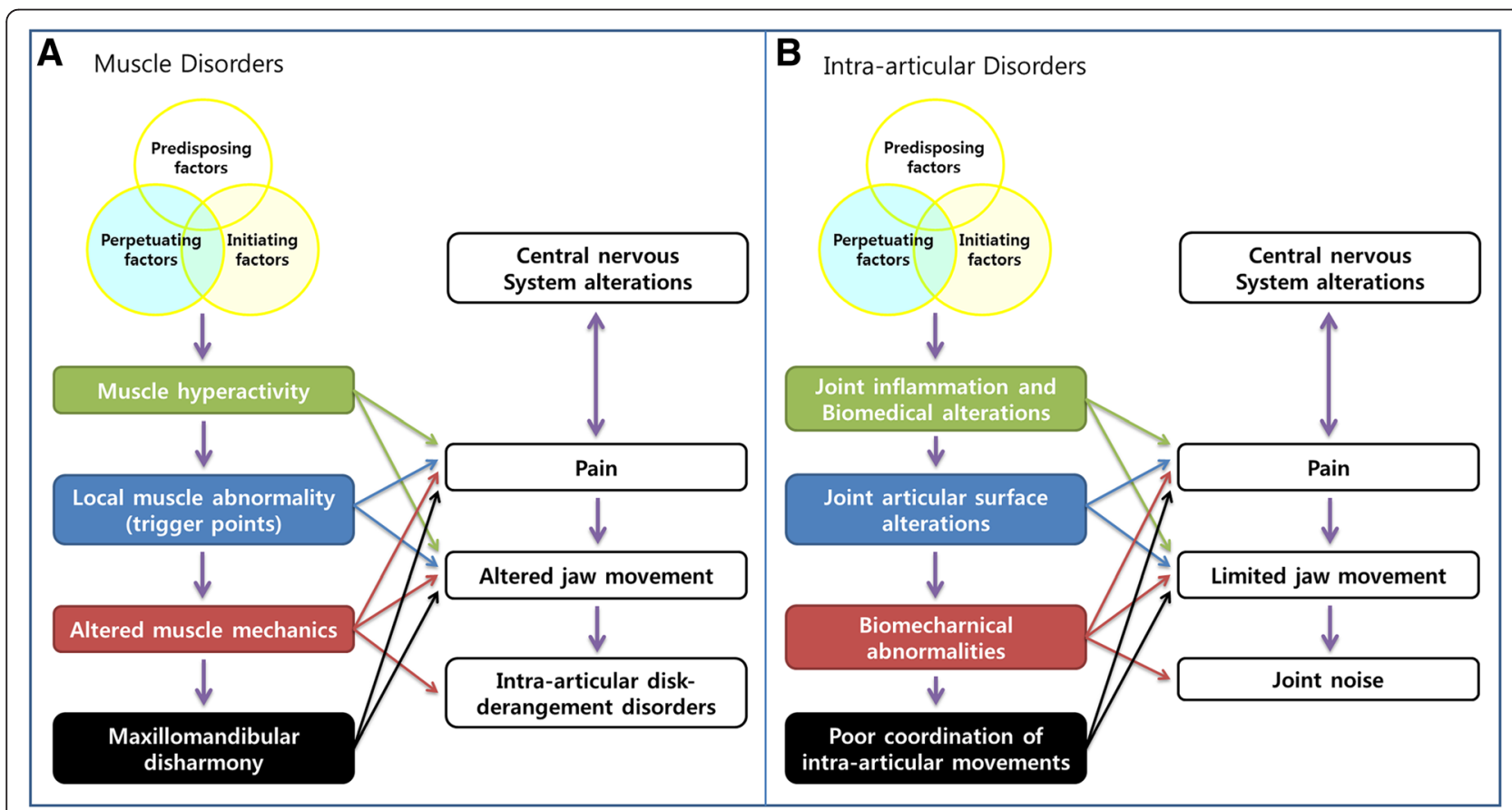

Figure 1 Pathogenesis of TMD. Adopted from Scrivani SJ, Keith DA, Kaban LB. Temporomandibular disorders. The New England journal of medicine 2008:359:2693-705 [4]. 
Table 1 Physical examination directed toward mandibular dysfunction

\begin{tabular}{ll}
\hline Examination & Observations \\
\hline Inspection & $\begin{array}{l}\text { Facial asymmetry, swelling, and masseter and temporal muscle hypertrophy Opening pattern (corrected and } \\
\text { uncorrected deviations, uncoordinated movements, limitations) }\end{array}$ \\
$\begin{array}{l}\text { Assessment of range of mandibular } \\
\text { movement }\end{array}$ & $\begin{array}{l}\text { Maximum opening with comfort, with pain, and with clinician assistance Maximum lateral and protrusive } \\
\text { movements }\end{array}$ \\
Palpation examination & $\begin{array}{l}\text { Masticatory muscles Temporomandibular joints Neck muscles and accessory muscles of the jaw Parotid and } \\
\text { submandibular areas Lymph nodes }\end{array}$ \\
Provocation tests & $\begin{array}{l}\text { Static pain test (mandibular resistance against pressure) Pain in the joints or muscles with tooth clenching } \\
\text { Reproduction of symptoms with chewing (wax, sugarless gum) } \\
\text { Intraoral examination }\end{array}$ \\
& $\begin{array}{l}\text { Signs of parafunction (cheek or lip biting, accentuated linea alba, scalloped tongue borders, occlusal wear, tooth } \\
\text { mobility, generalized sensitivity to percussion, thermal testing, multiple fractures of enamel, restorations) }\end{array}$
\end{tabular}

From De Rossi S, Stern I, Sollecito TP. Disorders of the masticatory muscles. Dental clinics of North America 2013;57:449-64; and Data from references [4,6,111-115].

make correct diagnoses and comprehensive treatment plans. MRI is not routinely performed on patients with DFD, thus clinical presentation, signs and symptoms, and standard radiographic images such as panoramic radiograph are used to make a correct diagnosis and implement further corresponding treatment modality [13] (Table 2).

\section{Treatment of Temporomandibular joint disorders}

Once a correct diagnosis is made from detailed clinical data, initial treatment must be started with reversible options including patient education, medications, physical therapy, and occlusal splint therapy. Minimally invasive options (eg, trigger point injections, Botox injections, arthrocentesis, or arthroscopy) are available for TMJ pain and dysfunction, and also open arthroplasty can be performed as later options when indicated (Table 3).

Most TMD symptoms (approximately 85-90\%) are treated with noninvasive, nonsurgical, and reversible interventions [13-15]. Patients with intra-articular disorder who has been refractory to nonsurgical treatment over 3 to 6 months with persistent pain and limited function would require a consideration for surgical interventions (Figure 4).

\section{Influences of temporomandibular joint disorder to dentofacial deformities}

Adaptive developmental changes on mandibular condyles [16] and post-developmental degenerative changes of mandibular condyles can create alteration on facial skeleton and occlusion $[17,18]$. Also, trauma or developmental deformity causing the changes in morphology and occlusion, can alter biomechanics of TMJ, consequently develop into TMJ internal derangement (TMD ID) [19].

Skeletal class II malocclusion in children has higher propensity for TMD symptoms [20]. Also, skeletal class II malocclusion, longer posterior facial height, and hyperdivergent profile tend to show increased severity of TMJ ID [21]. In a retrospective study including children younger than 14, the presence of TMD affects a normal development of facial bones, and can result in mandibular asymmetry [18]. And Legrell PE and Isberg A also demonstrated a development of mandibular asymmetry from the condyle-disc complex disorder after surgically altering unilateral TMJ disc in animal study [22]. Thus, TMD manifesting in a variety of symptoms, also can apply abnormal stress to mandibular condyles and affect its growth pattern of mandible [23].

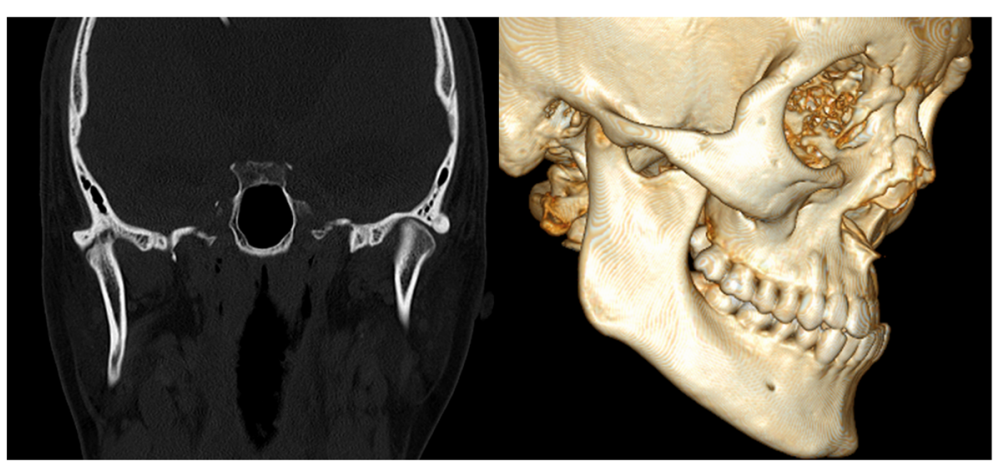

Figure $\mathbf{2}$ CT scan images of TMJ. Patients with history of trauma shows ankylosed TMJ on CT scan image, and 3D reconstruction demonstrates the overall shape of TMJ. 


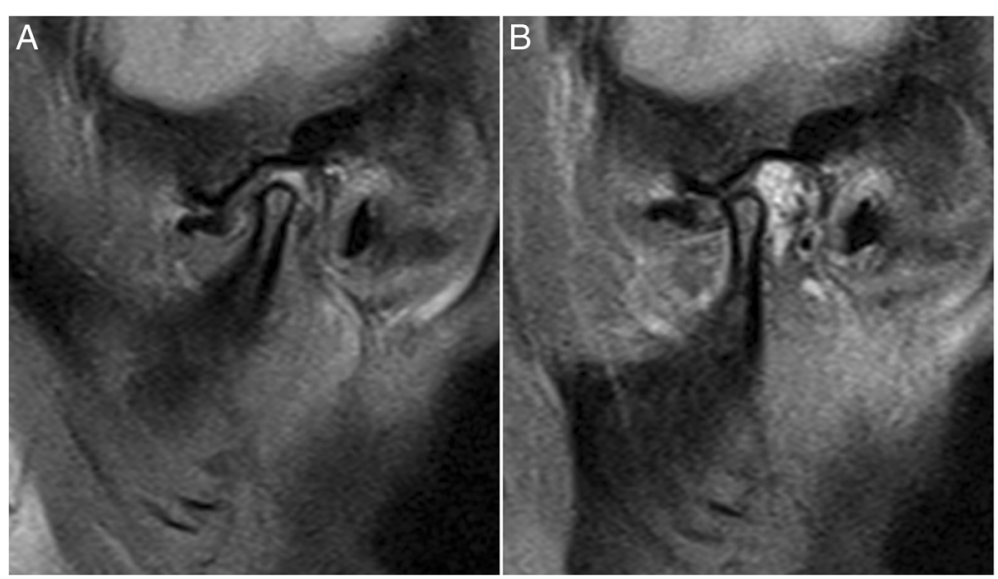

Figure 3 MRI Sagittal view showing disc displacement without reduction; A. Closed mouth; B. Open mouth.

Patients with bilateral TMJ ID tend to have a short ramus, clockwise rotation of mandible, and retrognathic mandible [24-27], while patients with unilateral TMJ ID present lateral displacement of mandible and deviated occlusal and mandibular plane [19]. The severity of TMJ ID is also associated with amount of displacement of Antegonion and Menton [28,29], and the growth pattern can be altered in maxilla as well as mandible [30]. Unilateral TMJ ID displays a deviation of mention to the affected side [28,29,31]. And reverse examination study also demonstrated positive correlations between short ramus and condyle as well as deviated mention being associated with TMJ disc displacement and derangement $[32,33]$. Thus, the severity of TMD and disc displacement can lead to mandibular hypoplasia or facial asymmetry [18]. Also, degenerative changes and resorption of manduibular condyle beyond growth completion can lead to changes in skeletal shape [34].

\section{Influence of orthognathic surgery to temporomandibular joint}

Many DFD patients desire to improve stomatognathic function and esthetics, as well as TMJ symptoms [35]. However, current literatures on the relationship between OGS and TMJ complications are still debatable [36]. Some authors claim that TMJ dysfunction can be improved after OGS, yet others claim deleterious effects on TMJ can occur after OGS $[37,38]$.

Routine OGS procedure involves surgical movement of upper jaw via LeFort I osteotomy and lower jaw via ramus osteotomy. LeFort I osteotomy is not associated with direct trauma to TMJ or masticatory musculature, thus there are only minimal effects on TMJ dysfunction or mandibular movement [39]. Therefore, This review article focused on mandibular surgical modalities which directly affect the mandibular range of motion, mastication, and TMJ symptom changes.

\section{Sagittal split ramus osteotomy (SSRO)}

SSRO is well known and very commonly used surgical technique worldwide for repositioning mandibular dental arch in both directions by advancement and setback movement of mandibular body [40]. SSRO provide a broad medullary contact between the bony segments that ensures stable healing capability. Internal fixation of bony segments eliminates or reduces the duration of intermaxillary fixation (IMF), plus a predictable immediate postoperative occlusion is achievable. The risk of neurovascular bundle injury is higher compared to intraoral vertical ramus osteotomy (IVRO) [41], and the risk of unfavorable fracture during the split between the bony segments was reported at $0.9 \%$ [42]. The risk of

Table 2 AAOP diagnostic classification of TMDs

\begin{tabular}{ll}
\hline Diagnostic Category & Diagnoses \\
\hline $\begin{array}{l}\text { Cranial bones (including the } \\
\text { mandible) }\end{array}$ & $\begin{array}{l}\text { Congenital and developmental disorders: aplasia, hypoplasia, hyperplasia, dysplasia (eg, first and second branchial } \\
\text { arch anomalies, hemifacial microsomia, Pierre Robin syndrome, Treacher Collins syndrome, condylar hyperplasia, } \\
\text { prognathism, fibrous dysplasia) Acquired disorders (neoplasia, fracture) }\end{array}$ \\
TMJ disorders & $\begin{array}{l}\text { Deviation in form Disc displacement (with reduction; without reduction) Dislocation Inflammatory conditions } \\
\text { (synovitis, capsulitis) Arthritides (osteoarthritis, osteoarthrosis, polyarthritides) Ankylosis (fibrous, bony) Neoplasia }\end{array}$ \\
Masticatory muscle disorders & Myofascial pain Myositis spasm Protective splinting Contracture
\end{tabular}

Adapted from Leeuw Rd, Klasser GD, American Academy of Orofacial P. Orofacial pain : guidelines for assessment, diagnosis, and management. 5th edition. Chicago: Quintessence Publishing; 2013. 


\begin{tabular}{ll}
$\begin{array}{l}\text { Table } 3 \text { Treatment of TMD symptoms in patients with } \\
\text { dentofacial deformity }\end{array}$ \\
\hline Reversible treatment of TMD & $\begin{array}{l}\text { Irreversible treatment } \\
\text { of TMD }\end{array}$ \\
\hline $\begin{array}{ll}\text { Patient Education } & \text { Trigger Point Injections } \\
\text { Medications: } & \text { Botox } \\
\text { Nonsteroidal anti-inflammatory drugs } & \text { Arthrocentesis } \\
\text { (anti-RA meds) } & \text { Arthroscopy } \\
\text { Muscle relaxants } & \text { Open Arthroplasty } \\
\text { Antidepressants } & \\
\text { Physical Therapy } & \\
\text { ROM exercised } & \\
\text { Passive stretching } & \\
\text { Spray and stretch } & \\
\text { Ultrasound } & \\
\text { Transcutaneous electrical nerve } & \\
\text { stimulation } & \\
\text { Occlusal Splint Therapy }\end{array}$
\end{tabular}

From Nale JC. Orthognathic Surgery and the Temporomandibular Joint Patient. Oral and maxillofacial surgery clinics of North America 2014;26:551-64 [116].

complications is reduced when experienced surgeons perform the procedure. Reproducing the original condylar position is difficult, and too much pressure can be placed against the articular disc or unfavorable condylar position can be created during SSRO. These conditions can potentially result in joint noise or pain, and can worsen any pre-existing TMD symptoms [43-47].

In association with mandibular setback surgery using SSRO, Ueki et al. [48] reported TMJ symptom relief in $66.7 \%$ of patients after SSRO, and $\mathrm{Hu} \mathrm{J}$ et al. [49] reported symptom improvement in $40 \%$ of patients, yet a development of new TMJ symptom in $8 \%$ after SSRO. Kerstens et al. [50] reported 66\% improvement of TMJ symptoms and $11.5 \%$ aggravation of symptoms while White and Dolwick [51] showed 89.1\% improvement, $2.7 \%$ no changes, and $8.1 \%$ aggravation in TMJ symptoms. Although small degree of postoperative posterior or lateral displacement of condyle can be made following SSRO in class III patients, however these minor changes do not create significant changes in TMJ disc position or postoperative pain [35,52-54].

TMJ remodeling is divided into functional and dysfunctional remodeling. Dysfunctional remodeling has a significant alteration of the joint or occlusion and can cause reduction of condylar-ramus height, mandibular setback leading to class II malocclusion $[55,56]$. Dysfunctional remodeling is also known as condylar resorption which can be induced from systemic and local arthritis or trauma. Because a clear etiology is not present, it is categorized as idiopathic condylar resorption (ICR).
Maxillomandibular complex counterclockwise rotation via LeFort I osteotomy and SSRO can increase the mechanical loading of TMJ, and can lead to postoperative relapse [57]. Patients with systemic diseases such as rheumatoid arthritis, scleroderma, systemic lupus erythematosus, and other vascular collagenous diseases are known as high risk factors for condylar resorption [58-61]. Predisposing factors for ICR are the presence of TMJ dysfunction, young woman, high mandibular plane angle, and posteriorly inclined condylar neck [59,61-66].

A large amount of mandibular advancement via SSRO should be avoided to prevent condylar resoprtion occurring from the tension of stretched surrounding soft-tissue components [67-69]. Internal fixation with monocortical miniplates and screws (1.5$8.9 \%)$ showed more favorable response to condylar resoprtion than using bicortical screws (2-50.3\%) during SSRO [70]. This is likely due to a torques being created on condyles from the proximal segment displacement during bicortical fixation [71]. The use of computer-aided design/computer-aided manufacturing-made condyle positioning jig has been suggested to minimize a significant condylar displacement or torque [72].

The postoperative relapse of open bite from condylar resorption usually occurs between 6 months to 3 year, thus a regular follow up is important to intervene early in the process [73]. Anti-inflammatory medication, tumor necrosis factor inhibitor, or matrix metalloproteinase inhibitor as pharmacotherapy [74], or an utilization of occlusal splints to reduce the joint loading [75] can help prevent resorption process. A total joint replacement option is also available if further active resorption process continues.

Zimmer et al. [76] reported that two-jaw surgery (maxillary advancement and mandibular setback surgery) had no influcence on mandibular mobility compared to a single-jaw surgery. Mandibular hypomobility is a common condition after mandibular advancement via SSRO especially with a prolonged IMF duration $[77,78]$, degenerative changes during the periods of IMF [79], masticatory muscle unused atrophy, and decrease in muscle energy reserves due to immobilization $[80,81]$. Atrophy of human skeletal muscles and a decrease in strength and muscle energy reserves have also been associated with immobilization [80]. Aragon et al. recommended a sound postoperative rehabilitation program following orthognathic procedures to prevent hypomobility [82].

\section{Intraoral vertical ramus osteotomy (IVRO)}

IVRO is one of mandibular osteotomy techniques commonly used for mandibular setback procedure [83-86]. A 


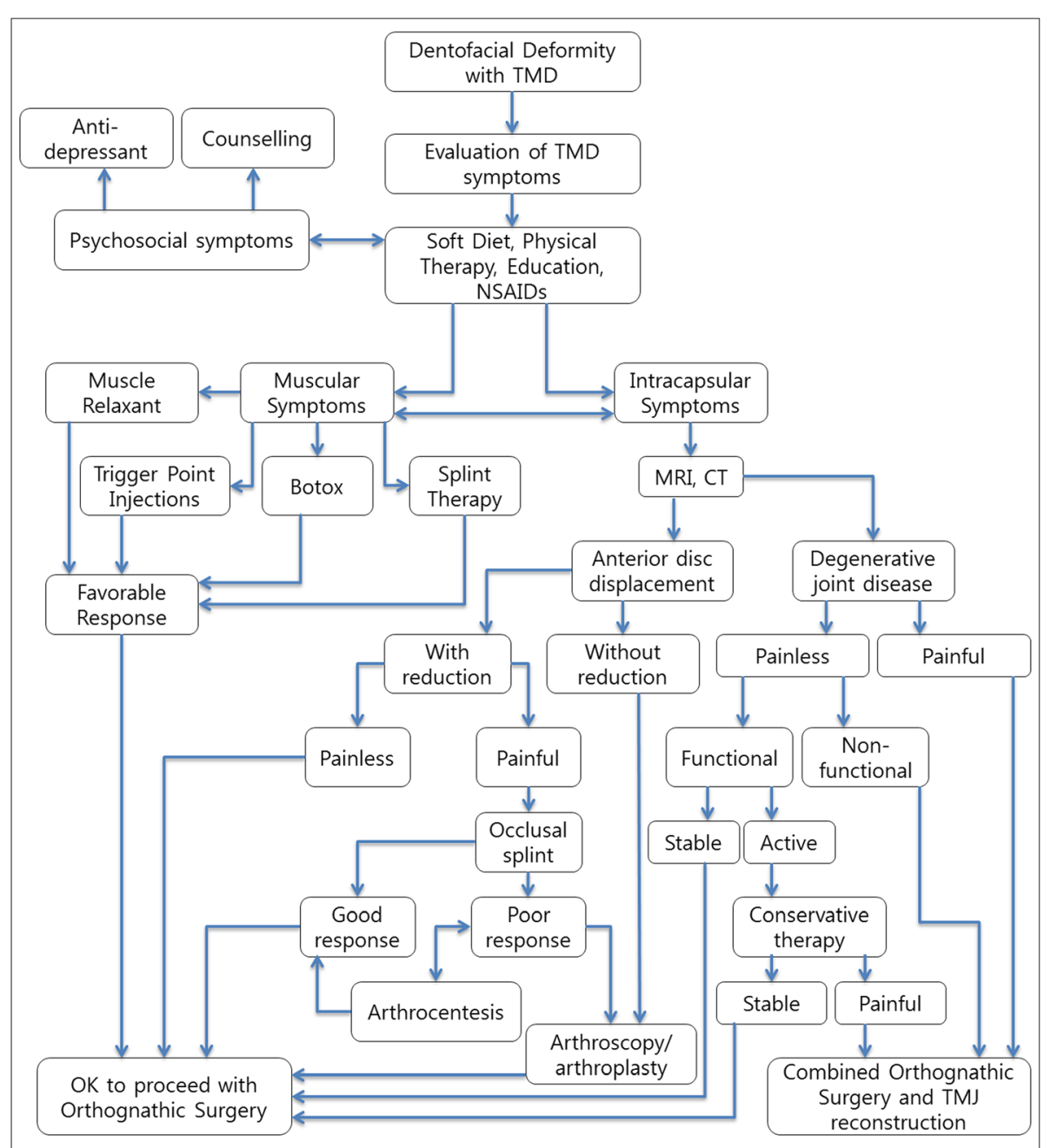

Figure 4 Flow diagram and treatment algorithm for patients with dentofacial deformity and TMD symptoms. Adopted from Nale, J.C. Orthognathic Surgery and the Temporomandibular Joint Patient. Oral and maxillofacial surgery clinics of North America 2014;26:551-64 [116].

vertical osteotomy is made posterior to lingula, and proximal segment is placed lateral to distal segment without internal rigid fixation. It is relatively simple procedure and surgical time is much reduced compared to SSRO. Also, the risk of inferior alveolar nerve damage and neurologic deficit is lower $[87,88]$. Less than $1 \mathrm{~mm}$ of posterior relapse can occur after mandibular setback via IVRO, but the risk of further relapse is low and overcorrection is not commonly indicated [89]. Increased in transverse facial width from laterally positioned proximal segment is less than $1 \%$ due to continuing remodeling process [90].

A drawback of IVRO is the requirement of IMF since internal rigid fixation is not performed, and some clinicians recommend more than 4 weeks of IMF postoperatively [91-94]. However, active physical therapy with less than 2 weeks of IMF demonstrated a stable occlusion and good bone healing [95], (Table 4) Some study reported just one- day of IMF followed by early jaw exercise being sufficient [96]. When initial bite is unstable, an active physical therapy with close follow-ups, and re-IMF protocol is used to obtain improved occlusion, and $88 \%$ of patients achieve a stable occlusion after IVRO within 10 days of active physical therapy and Maximum mouth opening (MMO) more than $30 \mathrm{~mm}$ [95].

IVRO requires a wide dissection of lateral aspect of ramus and medial aspect of proximal segment for muscle detachment. Freed proximal segment initially moves anterio-inferiorly and reduces the pressures on articular disc by physiologic equilibrium position and better condyle-disc relation [97]. Anterio-inferiorly moved condyle eventually returns back to its original position over time postoperatively [98].

Improvement of joint sound, pain, and other TMJ symptoms after IVRO is likely due to resting of TMJ and surrounding musculatures during IMF period as well as 


\section{Table 4 Active Physical Therapy instruction form for patients}

\section{Instructions for active physical therapy (Yonsei Protocol)}

It has been about 2 weeks after undergoing your jaw surgery. The purpose of this active physical therapy is to help your facial musculatures and jaws adapt into a new position from the surgery. Please follow the instructions in order to recover your original jaw movement and stable result.

1. Open your mouth as big as possible : Repeat 3 times

A. During the opening, check the lower incisal midline and do not allow laterally

B. deviated movement.

C. Close your mouth and lower tooth must be positioned into the splint without gap. If lower teeth are not positioned into the splint, try to close gap by pushing the jaw with your hands.

2. Move your lower jaw anteriorly : Repeat 3 times. From the original position, move your lower jaw anteriorly and move back to its original position. Check the midline of the lower teeth and do not allow laterally deviated movement.

3. Move your lower jaw to the left side : Repeat 3 times.

4. Move your lower jaw to the right side : Repeat 3 times.

5. Above instruction is 1 cycle. Please follow the instruction in order

6. You have to repeat above physical therapy protocol for 1 hour.

7. Then, you have to fix the lower jaw to upper jaw for 2 hours.

8. During the physical therapy, training elastics must be kept in the instructed site.

9. Please avoid relatively hard food and be careful not to break the splint.

The splint is removed after 1 to 2 weeks of physical therapy, depending on the progess. It is not easy, but please be patient until finishing the physical therapy. This physical therapy is continued about 1 month and this therapy makes stable functional results.

Department of Oral \& Maxillofacial Surgery Dental Hospital, Yonsei Medical Center

Adopted from Jung HD, Jung YS, Park JH, Park HS. Recovery pattern of mandibular movement by active physical therapy after bilateral transoral vertical ramus osteotomy. J Oral Maxillofac Surg 2012;70:e431-7.

the condylotomy effects from anterio-inferior movement of condyle [39,88,97-100]. IVRO was reported to have 50-100\% improvement of TMJ symptoms [101-104], and Jung et al. [105] reported 70.8\% 94.3\% improvement of joint sounds and $89.4 \%$ improvement of TMJ pain after IVRO. Ueki et al. [48] reported TMJ symptom improvement in class III patients $88 \%$ after IVRO and $66.7 \%$ after SSRO, but MRI study showed 50\% of improvement of anteriorly displaced disc after IVRO and no improvement after SSRO.

Horizontal condylar axis tend to be medially rotated when TMJ disc displacement or degenerative joint disease is present, and some authors suggested that medially rotated condyle is the etiological factor for TMD $[106,107]$. From this point of view, lateral rotation of condyle after IVRO is very effective improving TMJ symptoms. Choi et al. [108] evaluated 200 patients' postoperative changes in proximal segment and condyles on the transverse plane after IVRO using submentovertex cephalogram. This study reported 15.05 (SD: 8.97) of postoperative lateral rotation of condyles which slowly returned towards the original position, yet 4.53 (SD: $6.03)^{\circ}$ of lateral rotation remained at 1 year. This study included only class III malocclusion patients with low TMD prevalence and some patients were without known TMD. The condyles remained in laterally rotated position in all patients including the ones without known prior TMDs. Thus, laterally rotated condyles from IVRO improving TMD cannot be concluded from this study.

Condylar sagging in lateral or anterio-inferior direction can occur after IVRO. Condylar sagging can be avoided with careful dissection during the ramus osteotomy and not violating condylar capsules. In fact, the changes in the intercondylar distance on transverse plane after IVRO is not significant [108]. Excessive interference between the segments can induce sagging, thus reduction of bony interference or using a modified osteotomy design should be considered [109].

In order to prevent post OGS mandibular hypomobility, implementation of a sound postoperative rehabilitation program is very important [82]. The incidence of mandibular hypomobility after IVRO is very low and recovery of MMO is known to be $90-98 \%$ of pre-operative opening. Aragon et al. [82] showed 90\% of recovery in 13 patients, Storum and Bell [110] showed $98 \%$ of recovery on 24 patients, Boyd et al. [39] showed $98 \%$ of recovery in 9 patients, and Jung et al. [95] reported $91.3 \%$ of recovery in 187 patients within 6 month and 95.7\% recovery at 24 month after the procedure (Figure $5 \mathrm{~A}$ ). Patients with MMO less than $40 \mathrm{~mm}$ showed 112.5 to $123.2 \%$ recovery after IVRO procedure (Figure $5 \mathrm{~B}$ ).

\section{Conclusion}

The changes of facial skeleton in DFD patients after OGS have an impact on TMJ, masticatory musculature, and surrounding soft tissues. Patients with TMJ symptoms requires a thorough evaluation including history taking, focused physical examination, and imaging modalities such as CT or MRI as indicated in order to obtain correct diagnoses and treatments prior to OGS. These evaluations are performed pre, intra, and postoperatively to determine the status of TMJ condition and managed appropriately. The changes of TMJ symptoms after OGS are associated with multiple factors including masticatory and facial musculature, and improvement in disc-condyle relationship as well as psychological factor. Any surgical procedures involving mandibular osteotomy can directly affect TMD, thus, pre-existing TMJ symptoms and diagnoses should be considered prior to treatment planning and OGS. 

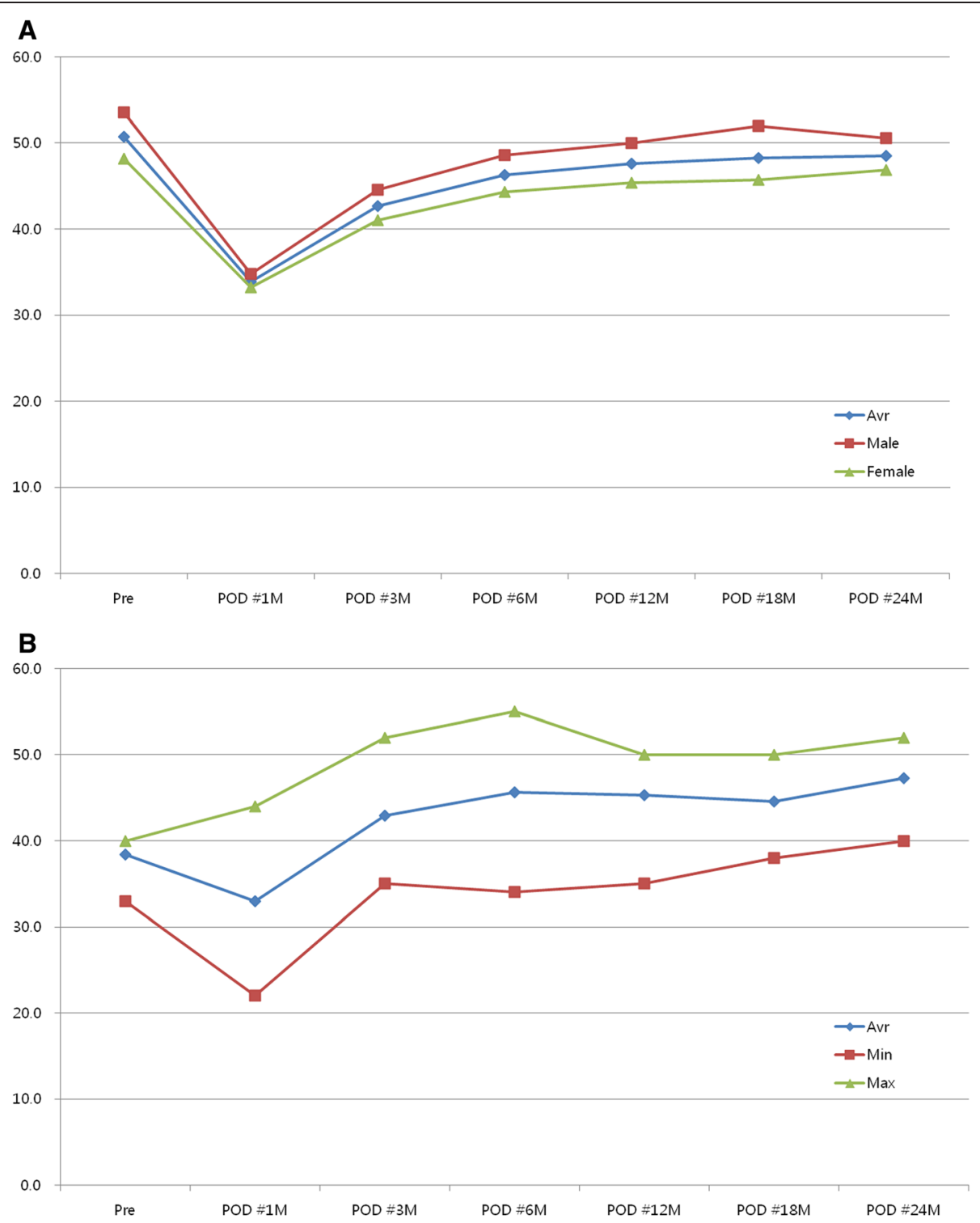

Figure 5 Recovery pattern following IVRO. A. Chronologic changes in the range of mandibular movement (maximal mouth opening). B. Chronologic changes in the range of mandibular movement (maximal mouth opening) in mandibular hypomobility patients. Abbreviations: Avr, average; POD, postoperative day. Adopted from Jung $\mathrm{H}$ et al. Recovery pattern of mandibular movement by active physical therapy after bilateral transoral vertical ramus osteotomy. Journal of oral and maxillofacial surgery 2012;70:e431-7 [95].

\section{Competing interest}

The authors declare that they have no competing interests.

\section{Authors' contribution}

Conception and design of study/review/case series: HDJ, YSJ Acquisition of data: laboratory or clinical/literature search: SYK, HSP Analysis and interpretation of data collected: HDJ, SYK, HSP Drafting of article and/or critical revision: HDJ, SYK Final approval and guarantor of manuscript: HDJ, YSJ. All authors read and approved the final manuscript.

\section{Acknowledgements}

This article was supported by a faculty research grant of Yonsei University College of Dentistry for 2014 (6-2014-0101).

\section{Author details}

${ }^{1}$ Department of Oral \& Maxillofacial Surgery, Yonsei University College of Dentistry, Seoul, South Korea. ${ }^{2}$ Private Practice Vienna VA; Former resident Harvard Oral \& Maxillofacial Surgery, Boston, MA, USA.

\section{Received: 25 March 2015 Accepted: 22 April 2015}

Published online: 28 May 2015

\section{References}

1. Pirttiniemi PM (1994) Associations of mandibular and facial asymmetries-a review. Am J Orthod Dentofac Orthop 106:191-200

2. Buttke TM, Proffit WR (1999) Referring adult patients for orthodontic treatment. J Am Dent Assoc 130:73-9

3. Wadhwa S, Kapila S (2008) TMJ disorders: future innovations in diagnostics and therapeutics. J Dent Educ 72:930-47 
4. Scrivani SJ, Keith DA, Kaban LB (2008) Temporomandibular disorders. N Engl J Med 359:2693-705

5. De Rossi S, Greenberg MS, Liu F, Steinkeler A (2014) Temporomandibular disorders: evaluation and management. Med Clin North Am 98:1353-84

6. Lipton JA, Ship JA, Larach RD (1993) Estimated prevalence and distribution of reported orofacial pain in the United States. J Am Dent Assoc 124:115-21

7. Manfredini D, Guarda Nardini L, Winocur E, Piccotti F, Ahlberg J, Lobbezoo F (2011) Research diagnostic criteria for temporomandibular disorders: a systematic review of axis I epidemiologic findings. Oral surgery, oral medicine, oral pathology, oral radiology and endodontology 112:453-62

8. Abubaker AO, Raslan WF, Sotereanos GC (1993) Estrogen and progesterone receptors in temporomandibular joint discs of symptomatic and asymptomatic persons: a preliminary study. J Oral Maxillofac Surg 51:1096-100

9. Milam SB, Aufdemorte TB, Sheridan PJ, Triplett RG, Van Sickels JE, Holt GR (1987) Sexual dimorphism in the distribution of estrogen receptors in the temporomandibular joint complex of the baboon. Oral surgery, oral medicine, oral pathology 64:527-32

10. Aufdemorte TB, Van Sickels JE, Dolwick MF, Sheridan PJ, Holt GR, Aragon SB et al (1986) Estrogen receptors in the temporomandibular joint of the baboon (Papio cynocephalus): an autoradiographic study. Oral surgery, oral medicine, oral pathology 61:307-14

11. De Rossi S, Stern I, Sollecito TP (2013) Disorders of the masticatory muscles. Dent Clin N Am 57:449-64

12. Tasaki MM, Westesson PL (1993) Temporomandibular joint: diagnostic accuracy with sagittal and coronal MR imaging. Radiology 186:723-9

13. Leeuw R, Klasser GD, American Academy of Orofacial P (2013) Orofacial pain. In: guidelines for assessment, diagnosis, and management

14. McCain JP, Sanders B, Koslin MG, Quinn JH, Peters PB, Indresano AT (1992) Temporomandibular joint arthroscopy: a 6-year multicenter retrospective study of 4,831 joints. J Oral Maxillofac Surg 50:926-30

15. Israel HA, Part I (1999) The use of arthroscopic surgery for treatment of temporomandibular joint disorders. J Oral Maxillofac Surg 57:579-82

16. Shen G, Darendeliler MA (2005) The adaptive remodeling of condylar cartilage--a transition from chondrogenesis to osteogenesis. J Dent Res 84:691-9

17. Mongini $F(1983)$ Influence of function on temporomandibular joint remodeling and degenerative disease. Dent Clin N Am 27:479-94

18. Schellhas KP, Pollei SR, Wilkes CH (1993) Pediatric internal derangements of the temporomandibular joint: effect on facial development. Am J Orthod Dentofac Orthop 104:51-9

19. Inui M, Fushima K, Sato S (1999) Facial asymmetry in temporomandibular joint disorders. J Oral Rehabil 26:402-6

20. Riolo ML, Brandt D, TenHave TR (1987) Associations between occlusal characteristics and signs and symptoms of TMJ dysfunction in children and young adults. Am J Orthod Dentofac Orthop 92:467-77

21. Jung WS, Kim H, Jeon DM, Mah SJ, Ahn SJ (2013) Magnetic resonance imaging-verified temporomandibular joint disk displacement in relation to sagittal and vertical jaw deformities. Int J Oral Maxillofac Surg 42:1108-15

22. Legrell PE, Isberg A (1999) Mandibular length and midline asymmetry after experimentally induced temporomandibular joint disk displacement in rabbits. Am J Orthod Dentofac Orthop 115:247-53

23. Hellsing G, Holmlund A (1985) Development of anterior disk displacement in the temporomandibular joint: an autopsy study. J Prosthet Dent 53:397-401

24. Ahn S, Kim T, Nahm D (2004) Cephalometric keys to internal derangement of temporomandibular joint in women with Class II malocclusions. Am J Orthod Dentofac Orthop 126:486-94, discussion 94

25. Bryndahl F, Eriksson L, Legrell PE, Isberg A (2006) Bilateral TMJ disk displacement induces mandibular retrognathia. J Dent Res 85:1118-23

26. Byun E, Ahn S, Kim T (2005) Relationship between internal derangement of the temporomandibular joint and dentofacial morphology in women with anterior open bite. Am J Orthod Dentofac Orthop 128:87-95

27. Yang I, Moon B, Lee S, Ahn S (2012) Skeletal differences in patients with temporomandibular joint disc displacement according to sagittal jaw relationship. J Oral Maxillofac Surg 70:e349-60

28. Nakagawa S, Sakabe J, Nakajima I, Akasaka M (2002) Relationship between functional disc position and mandibular displacement in adolescent females: posteroanterior cephalograms and magnetic resonance imaging retrospective study. J Oral Rehabil 29:417-22

29. Trpkova B, Major P, Nebbe B, Prasad N (2000) Craniofacial asymmetry and temporomandibular joint internal derangement in female adolescents: a posteroanterior cephalometric study. Angle orthod 70:81-8
30. Maglione HO, de Zavaleta LA, Laraudo J, Falisi G, Fernandez F (2013) Temporomandibular dysfunction: internal derangement associated with facial and/or mandibular asymmetry. Cranio. J craniomandibular \& sleep practice 31:276-82

31. Ahn S, Lee S, Nahm D (2005) Relationship between temporomandibular joint internal derangement and facial asymmetry in women. Am J Orthod Dentofac Orthop 128:583-91

32. Choi H, Kim T, Ahn S, Lee S, Donatelli RE (2011) The relationship between temporomandibular joint disk displacement and mandibular asymmetry in skeletal Class III patients. Angle orthod 81:624-31

33. Tallents RH, Guay JA, Katzberg RW, Murphy W, Proskin H (1991) Angular and linear comparisons with unilateral mandibular asymmetry. J craniomandibular disorders 5:135-42

34. Schellhas KP, Piper MA, Omlie MR (1990) Facial skeleton remodeling due to temporomandibular joint degeneration: an imaging study of 100 patients. AJNR Am J Neuroradiol 11:541-51

35. Farella M, Michelotti A, Bocchino T, Cimino R, Laino A, Steenks MH (2007) Effects of orthognathic surgery for class III malocclusion on signs and symptoms of temporomandibular disorders and on pressure pain thresholds of the jaw muscles. Int J Oral Maxillofac Surg 36:583-7

36. lannetti G, Fadda TM, Riccardi E, Mitro V, Filiaci F (2013) Our experience in complications of orthognathic surgery: a retrospective study on 3236 patients. Eur Rev Med Pharmacol Sci 17:379-84

37. Dujoncquoy JP, Ferri J, Raoul G, Kleinheinz J (2010) Temporomandibular joint dysfunction and orthognathic surgery: a retrospective study. Head Face Med 6:27

38. Bays RA, Bouloux GF (2003) Complications of orthognathic surgery. Oral Maxillofac Surg Clin North Am 15:229-42

39. Boyd SB, Karas ND, Sinn DP (1991) Recovery of mandibular mobility following orthognathic surgery. J Oral Maxillofac Surg 49:924-31

40. Trauner R, Obwegeser $H$ (1957) The surgical correction of mandibular prognathism and retrognathia with consideration of genioplasty. I. Surgical procedures to correct mandibular prognathism and reshaping of the chin. Oral surgery, oral medicine, oral pathology 10:677-89, contd

41. Bell WH (1992) Modern practice in orthognathic and reconstructive surgery. Saunders, Philadelphia, pp 2111-37

42. Maclntosh RB (1981) Experience with the sagittal osteotomy of the mandibular ramus: a 13-year review. J Maxillofac Surg 9:151-65

43. Hackney FL, Van Sickels JE, Nummikoski PV (1989) Condylar displacement and temporomandibular joint dysfunction following bilateral sagittal split osteotomy and rigid fixation. J Oral Maxillofac Surg 47:223-7

44. Ellis E, Hinton RJ (1991) Histologic examination of the temporomandibular joint after mandibular advancement with and without rigid fixation: an experimental investigation in adult Macaca mulatta. J Oral Maxillofac Surg 49:1316-27

45. Buckley MJ, Tulloch JF, White RP, Tucker MR (1989) Complications of orthognathic surgery: a comparison between wire fixation and rigid internal fixation. Int J Adult Orthodon Orthognath Surg 4:69-74

46. O'Ryan F, Epker BN (1983) Surgical orthodontics and the temporomandibular joint. II. Mandibular advancement via modified sagittal split ramus osteotomies. Am J Orthod 83:418-27

47. Feinerman DM, Piecuch JF (1995) Long-term effects of orthognathic surgery on the temporomandibular joint: comparison of rigid and nonrigid fixation methods. Int J Oral Maxillofac Surg 24:268-72

48. Ueki K, Marukawa K, Nakagawa K, Yamamoto E (2002) Condylar and temporomandibular joint disc positions after mandibular osteotomy for prognathism. J Oral Maxillofac Surg 60:1424-32, discussion 32

49. Hu J, Wang D, Zou S (2000) Effects of mandibular setback on the temporomandibular joint: a comparison of oblique and sagittal split ramus osteotomy. J Oral Maxillofac Surg 58:375-80, discussion 80

50. Kerstens HC, Tuinzing DB, van der Kwast WA (1989) Temporomandibular joint symptoms in orthognathic surgery. J Craniomaxillofac Surg 17:215-8

51. White CS, Dolwick MF (1992) Prevalence and variance of temporomandibular dysfunction in orthognathic surgery patients. Int J Adult Orthodon Orthognath Surg 7:7-14

52. Kim Y, Yun P, Ahn J, Kim J, Kim S (2009) Changes in the temporomandibular joint disc position after orthognathic surgery. Oral surgery, oral medicine, oral pathology, oral radiology and endodontology 108:15-21

53. Ueki K, Nakagawa K, Takatsuka S, Yamamoto E (2006) The change of stress distribution on the condyle after mandibular setback surgery. Eur J Orthod 28:433-9 
54. Fang B, Shen GF, Yang C et al (2009) Changes in condylar and joint disC positions after bilateral sagittal split ramus osteotomy for correction of mandibular prognathism. Int J Oral Maxillofac Surg 38:726-30

55. Arnett GW, Milam SB, Gottesman L (1996) Progressive mandibular retrusion-idiopathic condylar resorption. Part I. Am J Orthod Dentofac Orthop 110:8-15

56. Arnett GW, Milam SB, Gottesman L (1996) Progressive mandibular retrusion-idiopathic condylar resorption. Part II. Am J Orthod Dentofac Orthop 110:117-27

57. Hoppenreijs TJ, Stoelinga PJ, Grace KL, Robben CM (1999) Long-term evaluation of patients with progressive condylar resorption following orthognathic surgery. Int J Oral Maxillofac Surg 28:411-8

58. Lanigan DT, Myall RW, West RA, McNeill RW (1979) Condylysis in a patient with a mixed collagen vascular disease. Oral surgery, oral medicine, oral pathology 48:198-204

59. Huang YL, Pogrel MA, Kaban LB (1997) Diagnosis and management of condylar resorption. J Oral Maxillofac Surg 55:114-9, discussion 9

60. Haers PE, Sailer HF (1995) Mandibular resorption due to systemic sclerosis. Case report of surgical correction of a secondary open bite deformity. Int J Oral Maxillofac Surg 24:261-7

61. Kerstens HC, Tuinzing DB, Golding RP, van der Kwast WA (1990) Condylar atrophy and osteoarthrosis after bimaxillary surgery. Oral surgery, oral medicine, oral pathology 69:274-80

62. Moore KE, Gooris PJ, Stoelinga PJ (1991) The contributing role of condylar resorption to skeletal relapse following mandibular advancement surgery: report of five cases. J Oral Maxillofac Surg 49:448-60

63. Merkx MA, Van Damme PA (1994) Condylar resorption after orthognathic surgery. Evaluation of treatment in 8 patients. J Craniomaxillofac Surg 22:53-8

64. Hoppenreijs TJ, Freihofer HP, Stoelinga PJ, Tuinzing DB, van't Hof MA (1998) Condylar remodelling and resorption after Le Fort I and bimaxillary osteotomies in patients with anterior open bite. A clinical and radiological study. Int J Oral Maxillofac Surg 27:81-91

65. Hwang SJ, Haers PE, Sailer HF (2000) The role of a posteriorly inclined condylar neck in condylar resorption after orthognathic surgery. J Craniomaxillofac Surg 28:85-90

66. Hwang SJ, Haers PE, Zimmermann A, Oechslin C, Seifert B, Sailer HF (2000) Surgical risk factors for condylar resorption after orthognathic surgery. Oral surgery, oral medicine, oral pathology, oral radiology and endodontology 89:542-52

67. Kobayashi T, Izumi N, Kojima T, Sakagami N, Saito I, Saito C (2012) Progressive condylar resorption after mandibular advancement. $\mathrm{Br}$ J Oral Maxillofac Surg 50:176-80

68. Kawamata A, Fujishita M, Nagahara K, Kanematu N, Niwa K-i, Langlais RP (1998) Three-dimensional computed tomography evaluation of postsurgical condylar displacement after mandibular osteotomy. Oral Surgery, Oral Medicine, Oral Pathology, Oral Radiology, and Endodontology 85:371-6

69. Scheerlinck JPO, Stoelinga PJW, Blijdorp PA, Brouns JJA, Nijs MLL (1994) Sagittal split advancement osteotomies stabilized with miniplates. A 2-5-year follow-up. Int J Oral Maxillofac Surg 23:127-31

70. Joss CU, Vassalli IM (2009) Stability after bilateral sagittal split osteotomy advancement surgery with rigid internal fixation: a systematic review. J Oral Maxillofac Surg 67:301-13

71. Arnett GW, Gunson MJ (2013) Risk factors in the initiation of condylar resorption. Semin Orthod 19:81-8

72. Kim H, Baek S, Kim T, Choi J (2014) Evaluation of three-dimensional position change of the condylar head after orthognathic surgery using computer-aided design/computer-aided manufacturing-made condyle positioning jig. J Craniofac Surg 25:2002-7

73. Hoppenreijs TJM, Stoelinga PJW, Grace KL, Robben CMG (1999) Long-term evaluation of patients with progressive condylar resorption following orthognathic surgery. Int J Oral Maxillofac Surg 28:411-8

74. Gunson MJ, Arnett GW, Milam SB (2012) Pathophysiology and pharmacologic control of osseous mandibular condylar resorption. J Ora Maxillofac Surg 70:1918-34

75. Handelman CS, Greene CS (2013) Progressive/idiopathic condylar resorption: an orthodontic perspective. Semin Orthod 19:55-70

76. Zimmer B, Schwestka R, Kubein MD (1992) Changes in mandibular mobility after different procedures of orthognathic surgery. Eur J Orthod 14:188-97

77. Ueki K, Marukawa K, Hashiba Y, Nakagawa K, Degerliyurt K, Yamamoto E (2008) Assessment of the relationship between the recovery of maximum mandibular opening and the maxillomandibular fixation period after orthognathic surgery. J Oral Maxillofac Surg 66:486-91

78. White RP, Peters PB, Costich ER, Page HL (1969) Evaluation of sagittal split-ramus osteotomy in 17 patients. J Oral Surg 27:851-5

79. Glineburg RW, Laskin DM, Blaustein DI (1982) The effects of immobilization on the primate temporomandibular joint: a histologic and histochemical study. J Oral Maxillofac Surg 40:3-8

80. Lindboe CF, Platou CS (1982) Disuse atrophy of human skeletal muscle. An enzyme histochemical study. Acta Neuropathol 56:241-4

81. MacDougall JD, Ward GR, Sale DG, Sutton JR (1977) Biochemical adaptation of human skeletal muscle to heavy resistance training and immobilization. J Appl Physiol Respir Environ Exerc Physiol 43:700-3

82. Aragon SB, Van Sickles JE, Dolwick MF, Flanary CM (1985) The effects of orthognathic surgery on mandibular range of motion. J Oral Maxillofac Surg 43:938-43

83. Caldwell JB, Letterman GS (1954) Vertical osteotomy in the mandibular raml for correction of prognathism. J oral surg 12:185-202

84. Akin RK, Walters PJ (1975) Experience with the intraoral vertical subcondylar osteotomy. J oral surg 33:342-5

85. Tornes K, Gilhuus Moe OT (1987) The surgical technique of vertical subcondylar osteotomy for correction of mandibular prognathism. A 10-year survey. Acta Odontol Scand 45:203-11

86. Fonseca RJ, Marciani RD, Turvey TA, Scully JR (2009) Oral and maxillofacial surgery. Vol. 3. Saunders Elsevier, St. Louis, Mo, pp 119-29

87. Astrand P, Ridell A (1973) Positional changes of the mandible and the upper and lower anterior teeth after oblique sliding osteotomy of the mandibular rami. A roentgen-cephalometric study of 55 patients. Scand J Plast Reconstr Surg 7:120-9

88. Hall HD, McKenna SJ (1987) Further refinement and evaluation of intraoral vertical ramus osteotomy. J Oral Maxillofac Surg 45:684-8

89. Jung H, Jung Y, Kim SY, Kim DW, Park H (2013) Postoperative stability following bilateral intraoral vertical ramus osteotomy based on amount of setback. Br J Oral Maxillofac Surg 51:822-6

90. Jung Y, Kim SY, Park S, Choi Y, Park H (2010) Changes of transverse mandibular width after intraoral vertical ramus osteotomy. Oral surgery, oral medicine, oral pathology, oral radiology and endodontology 110:25-31

91. Greebe RB, Tuinzing DB (1982) Overcorrection and relapse after the intraoral vertical ramus osteotomy. A one-year postoperative review of thirty-five patients. Oral surgery, oral medicine, oral pathology 54:382-4

92. Ayoub AF, Millett DT, Hasan S (2000) Evaluation of skeletal stability following surgical correction of mandibular prognathism. Br J Oral Maxillofac Surg 38:305-11

93. Lai SS, Tseng Y, Huang IY, Yang Y, Shen Y, Chen C (2007) Skeletal changes after modified intraoral vertical ramus osteotomy for correction of mandibular prognathism. J Plast Reconstr Aesthet Surg 60:139-45

94. Chen C, Lee H, Yang C et al (2008) Intraoral vertical ramus osteotomy for correction of mandibular prognathism: long-term stability. Ann Plast Surg 61:52-5

95. Jung H, Jung $Y$, Park JH, Park H (2012) Recovery pattern of mandibular movement by active physical therapy after bilateral transoral vertical ramus osteotomy. J Oral Maxillofac Surg 70:e431-7

96. Ohba S, Tasaki H, Tobita T et al (2013) Assessment of skeletal stability of intraoral vertical ramus osteotomy with one-day maxillary-mandibular fixation followed by early jaw exercise. J Craniomaxillofac Surg 41:586-92

97. Ueki K, Marukawa K, Shimada M et al (2007) Condylar and disc positions after intraoral vertical ramus osteotomy with and without a Le Fort osteotomy. Int J Oral Maxillofac Surg 36:207-13

98. Bell WH, Yamaguchi Y (1991) Condyle position and mobility before and after intraoral vertical ramus osteotomies and neuromuscular rehabilitation. Int J Adult Orthodon Orthognath Surg 6:97-104

99. Astrand P, Ericson S (1974) Relation between fragments after oblique sliding osteotomy of the mandibular rami and its influence on postoperative conditions. Int J Oral Surg 3:49-59

100. Egyedi P, Houwing M, Juten E (1981) The oblique subcondylar osteotomy: report of results of 100 cases. J oral surg 39:871-3

101. Bell WH, Yamaguchi Y, Poor MR (1990) Treatment of temporomandibular joint dysfunction by intraoral vertical ramus osteotomy. Int J Adult Orthodon Orthognath Surg 5:9-27 
102. Hall HD, Navarro EZ, Gibbs SJ (2000) Prospective study of modified condylotomy for treatment of nonreducing disk displacement. Oral surgery, oral medicine, oral pathology, oral radiology and endodontology 89:147-58

103. Hall HD, Navarro EZ, Gibbs SJ (2000) One- and three-year prospective outcome study of modified condylotomy for treatment of reducing disc displacement. J Oral Maxillofac Surg 58:7-17, discussion 8

104. Choi Y, Yun K, Kim S (2002) Long-term results of different condylotomy designs for the management of temporomandibular joint disorders. Oral surgery, oral medicine, oral pathology, oral radiology and endodontology 93:132-7

105. Jung H, Jung Y, Park H (2009) The chronologic prevalence of temporomandibular joint disorders associated with bilateral intraoral vertical ramus osteotomy. J Oral Maxillofac Surg 67:797-803

106. Westesson PL, Liedberg J (1987) Horizontal condylar angle in relation to internal derangement of the temporomandibular joint. Oral surgery, oral medicine, oral pathology 64:391-4

107. Fernández Sanromán J, Gómez González JM, del Hoyo JA (1998) Relationship between condylar position, dentofacial deformity and temporomandibular joint dysfunction: an MRI and CT prospective study. J Craniomaxillofac Surg 26:35-42

108. Choi YS, Jung H, Kim SY, Park H, Jung Y (2013) Remodelling pattern of the ramus on submentovertex cephalographs after intraoral vertical ramus osteotomy. Br J Oral Maxillofac Surg 51:e259-62

109. Jung H, Kim SY, Park H, Jung Y (2014) Modification of intraoral vertical ramus osteotomy. Br J Oral Maxillofac Surg 52:866-7

110. Storum KA, Bell WH (1986) The effect of physical rehabilitation on mandibular function after ramus osteotomies. J Oral Maxillofac Surg 44:94-9

111. Schiffman EL, Fricton JR, Haley DP, Shapiro BL (1990) The prevalence and treatment needs of subjects with temporomandibular disorders. J Am Dent Assoc 120:295-303

112. Kurita K, Westesson PL, Yuasa H, Toyama M, Machida J, Ogi N (1998) Natural course of untreated symptomatic temporomandibular joint disc displacement without reduction. J Dent Res 77:361-5

113. Milam SB (2006) TMJ osteoarthritis. In: Laskin DM, Greene CS, Hylander WL (eds) Temporomandibular disorders : an evidence-based approach to diagnosis and treatment. Quintessence Pub, Chicago, pp 105-23

114. Rammelsberg P, LeResche L, Dworkin S, Mancl L (2003) Longitudinal outcome of temporomandibular disorders: a 5-year epidemiologic study of muscle disorders defined by research diagnostic criteria for temporomandibular disorders. J Orofac Pain 17:9-20

115. Clark GT, Seligman DA, Solberg WK, Pullinger AG (1989) Guidelines for the examination and diagnosis of temporomandibular disorders. J Craniomandib Disord 3:7-14

116. Nale JC (2014) Orthognathic surgery and the temporomandibular joint patient. Oral Maxillofac Surg Clin North Am 26:551-64

\section{Submit your manuscript to a SpringerOpen ${ }^{\circ}$ journal and benefit from:}

- Convenient online submission

- Rigorous peer review

- Immediate publication on acceptance

- Open access: articles freely available online

- High visibility within the field

- Retaining the copyright to your article

Submit your next manuscript at $\gg$ springeropen.com 